\title{
Associations between School Readiness and Student Wellbeing: A Six-Year Follow Up Study
}

\author{
T. Gregory ${ }^{1,2}$ (D) E. Dal Grande ${ }^{1}$ (D) $\cdot$ M. Brushe ${ }^{1,2}$ (D) D. Engelhardt ${ }^{3}$. \\ S. Luddy ${ }^{3} \cdot$ M. Guhn ${ }^{4}$ (D) A. Gadermann ${ }^{4}$ (D) K.A. Schonert-Reichl ${ }^{5}$. \\ S. Brinkman ${ }^{1,2}$ (D)
}

Accepted: 21 July 2020 / Published online: 6 August 2020

(C) The Author(s) 2020

\begin{abstract}
It is well established that children's school readiness is associated with their later academic achievement, but less is known about whether school readiness is also associated with other measures of school success, such as students' social and emotional wellbeing. While some previous research has shown a link between early social and emotional development and student wellbeing, results are mixed and the strength of these relationships vary depending on whether data is based on child, teachers or parents ratings and which specific student wellbeing outcomes are measured. The present study explored the association between teacher-rated school readiness $\left(\mathrm{M}_{\text {age }}=\right.$ 5.6 years) across five developmental domains (physical, social, emotional, language and cognitive, and communication and general knowledge) and four aspects of student wellbeing (life satisfaction, optimism, sadness and worries) in Grade $6\left(\mathrm{M}_{\text {age }}=\right.$ 11.9 years) in a sample of 3906 Australian children. After adjustment for background child and family-level factors, children's early physical, social and emotional development were associated with all four wellbeing outcomes in Grade 6, but early language and cognitive skills and communication and general knowledge skills were only associated with internalising behaviours (sadness and worries). Mechanisms through which these different aspects of development might influence later wellbeing are discussed, as well as ways that schools and governments can support students' social and emotional wellbeing.
\end{abstract}

Keywords Child development · Social and emotional wellbeing $\cdot$ Life satisfaction · Optimism $\cdot$ Internalising behaviour $\cdot$ Subjective wellbeing

Electronic supplementary material The online version of this article (https://doi.org/10.1007/s12187-02009760-6) contains supplementary material, which is available to authorized users.

T. Gregory

tess.gregory@telethonkids.org.au

Extended author information available on the last page of the article 


\section{Introduction}

Previous research has established that school readiness across multiple developmental domains (physical, emotional, social, language, and cognitive) is associated with later measures of students success at school. Most of the research on school readiness and school success focuses on academic achievement as the primary measure of school success, and these studies tend to find that language and cognitive skills in preschool/ kindergarten show the largest associations with academic achievement (see La Paro and Pianta 2000 for review). However, many studies have shown that social and emotional skills at school entry are also associated with later academic achievement (Collie et al. 2018; Guhn et al. 2016), as well as other important life outcomes such as success in education, employment and public health outcomes in adulthood (Jones et al. 2015).

\subsection{Student Wellbeing: An Additional Measure of School Success}

Although academic achievement remains a central focus for education systems, fostering student wellbeing is increasingly seen as a central objective of education (British Columbia Ministry of Education 2015; Ministry of Education Singapore 2015; OECD 2015). For example, the Melbourne Declaration on Educational Goals for Young Australians states that all young Australians should have a sense of self-worth, confidence, self-awareness, optimism, resilience, empathy, respect for others, and the skills to form and maintain healthy relationships (Ministerial Council for Education Early Childhood Development and Youth Affairs 2008). Given this increased focus on student wellbeing as an important school outcome, it would be helpful to further understand the association between different aspects of school readiness and later student wellbeing, to help guide interventions programs that support school readiness, mental health and wellbeing in early childhood settings and schools. Previous studies have demonstrated an association between school readiness, including internalising/ externalising behaviours, fine and gross motor skills and language abilities in early childhood, and measures of student wellbeing in later childhood (Bart et al. 2007; Chow and Wehby 2018; Green et al. 2019), however few studies measure multiple aspects of school readiness and student wellbeing in a single study. The aim of this paper is to explore the association between school readiness on entry into elementary/ primary school across five developmental domains (physical health and wellbeing, social competence, emotional maturity, language and cognitive skills, and communication and general knowledge) and student wellbeing (life satisfaction, optimism, sadness and worries) measured 6 years later.

\subsection{Defining Student Wellbeing}

The term student wellbeing has been defined in many different ways (see Soutter et al. 2014, for review) but within the field of psychology it is most frequently operationalised by measures of subjective wellbeing (i.e. life satisfaction, positive and negative affect), positive traits/ character strengths (e.g. optimism, perseverance, prosocial skills), and the absence of psychological distress, such as sadness, worries and stress (Kern et al. 2015; Seligman and Csikszentmihalyi 2000; Soutter et al. 2014). It is these aspects of student wellbeing, which we refer to as social and emotional 
wellbeing, that are the focus of the current study. In line with the dual-factor model of mental health (Greenspoon and Saklafske 2001), which posits that positive indicators of wellbeing and negative indicators of distress or illness should be combined to provide a comprehensive measure of mental health, we focus on two positive indicators of social and emotional wellbeing (life satisfaction and optimism) and two negative indicators of social and emotional wellbeing (sadness and worries). In the next section, we provide a brief literature review on the links between school readiness and social and emotional wellbeing.

\subsection{School Readiness and Social and Emotional Wellbeing}

While there is a wealth of research into the correlates of life satisfaction and optimism (Diener et al. 1999; Orejudo et al. 2012; Thomson et al. 2015) there is very little research that explores associations between different aspects of school readiness, and these two social and emotional wellbeing constructs. One exception is a paper by Guhn et al. (2016) that explored the association between teacher-rated social, emotional, language and cognitive development in kindergarten and children's self-reported emotional wellbeing in Grade 4, with emotional wellbeing defined by a composite measure of optimism, life satisfaction and self-esteem. Measures of social, emotional and language/cognitive development at school entry all correlated with emotional wellbeing in Grade $4(\mathrm{r}=.11, .12$ and .05 respectively), but after entering all three development scores, gender, age and language background into a multilevel regression model, only emotional development was significantly associated with social and emotional wellbeing in Grade 4.

With respect to sadness and worries, studies tend to group the two together and focus on internalising behaviour. A large body of research shows that children who exhibit language problems at school entry are more likely to experience concurrent and future internalising behaviour problems (see Chow and Wehby 2018, for review). There is also evidence of a link between that social and emotional skills at school entry and later internalising behaviours. For example, a study by Romano et al. (2010) explored the association between social and emotional skills, maths and reading skills and attention, and internalising problems in the third grade in two Canadian datasets. In the parent-rated dataset (NLSCY), multiple aspects of social and emotional skills as well as maths skills were associated with internalising behaviours. Conversely, in the dataset where teachers rated social and emotional wellbeing (MLEPS), physical aggression was the only aspect of school readiness that was associated with internalising behaviours in third grade. The weaker associations between school readiness and social and emotional wellbeing in the teacher-rated dataset (MLEPS), may reflect the difficulties in observing internalising behaviours (sadness and worries) within a classroom setting. Smith (2007) discussed the challenges in measuring internalising behaviours in children and adolescents, and concluded that for older children, parents and children themselves are better informants than teachers of internalising behaviours.

To summarise, extant research suggests a link between the social and emotional aspects of school readiness and student wellbeing in later primary/ elementary school. However, the strength of these relationships seems to vary based on whether teachers, parents or the students themselves rate these skills. While there are clear associations between the language/cognitive aspects of school readiness and internalising 
behaviours, it remains unclear whether this extends to the positive aspects of wellbeing, such as life satisfaction and optimism. Key limitations of the previous literature include short follow up periods after school entry and limited adjustment for confounding child- and family-level variables such as gender, ethnicity, language background and socio-economic status that have been shown to impact on students' social and emotional wellbeing (World Health Organization 2008, 2012). While some research has longer follow-up periods (fourth or fifth grade), these studies generally only examine one or two broad social and emotional outcomes and there is a lack of research exploring life satisfaction and optimism specifically. There is also a reliance on teacher-report or parent-report of children's social and emotional outcomes, although research suggests that older children are the best informant of their internalising behaviours (Smith 2007).

\subsection{The Present Study}

The present study aims to build on and address the limitations of the previous literature by exploring the association between school readiness and students' social and emotional wellbeing in Grade 6, by linking data from two population datasets and adjusting for a range of child and family-level factors, which may act as confounders of the relationships between school readiness and student wellbeing. The first dataset - the Australian Early Development Census (AEDC) - provides teacher-rated data on children's development across five domains - physical health/wellbeing, social competence, emotional maturity, language/cognitive skills, and communication skills in their first year of full-time school (see Brinkman et al. 2014, for a description of the AEDC collection). The second dataset - the Wellbeing and Engagement Collection (WEC) - provides children's self-completed measures of life satisfaction, optimism, sadness and worries completed when the child was in sixth grade (see Gregory et al. 2019, for a description of the WEC collection). Based on the previous literature, we hypothesise that better social competence and emotional maturity when children start school will be associated with better social and emotional wellbeing in Grade 6, but that these effects will be small given the statistical adjustment for confounders and long follow-up period. We also hypothesis that children's language and communication skills at the start of school will be associated with their level of sadness and worries (internalising problems) in Grade 6.

\section{Method}

\subsection{Data Sources}

The AEDC is a national census of children's development in their first year of full time school completed by teachers in schools across Australia (Brinkman et al. 2014). This study utilised data from the first national census completed in 2009. Teachers complete the Australian version of the Early Development Instrument (see "Measures" for details) for all children in their class during the second term of the school year based on their observations of the children. Parents or guardians were informed by letter and were required to notify the school if they wished to exclude their child from the Census 
(i.e. opt-out consent procedures) and parents opted out of the AEDC in less than $3 \%$ of cases. In South Australia, where the current study was completed, data was collected for 16,207 children, and data was available for linkage for the $67.3 \%$ of children $(N=$ 10,908) who attended government/public schools (447 schools, see Fig. 1).

The Wellbeing and Engagement Collection (WEC) is an annual student completed survey administered by the Department for Education (DfE) in South Australia (Department for Education 2020). In 2015, all schools in South Australia with students in Grade 6, 7, 8 or 9 were invited to participate in the WEC, and the 2009

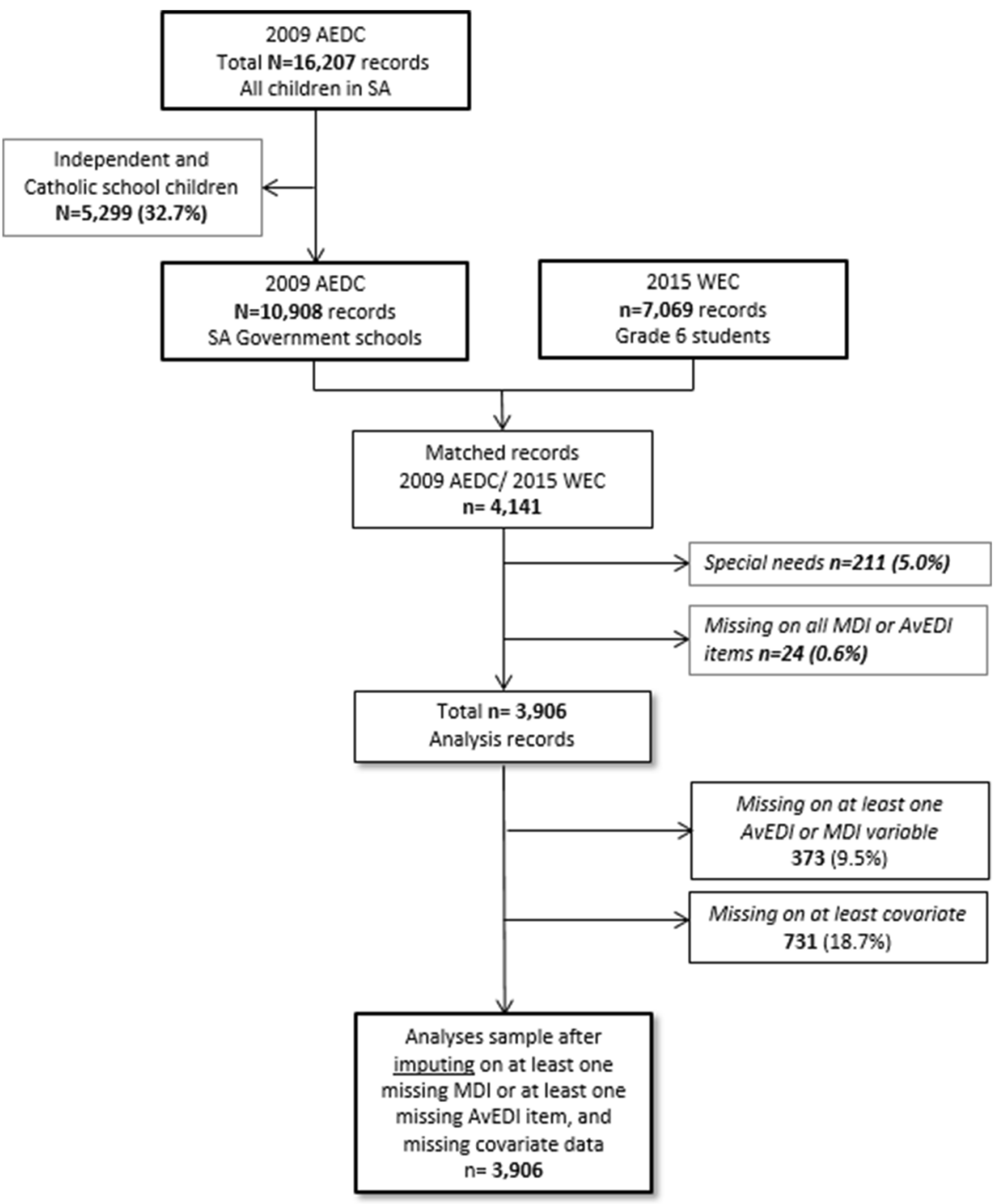

NOTE. AEDC $=$ Australian Early Development Census; $\mathrm{WEC}=$ Wellbeing and Engagement Collection, $\mathrm{MDI}=$ Middle Years Development Instrument, AvEDI = Australian version of the Early Development Instrument; SA = South Australian

Fig. 1 Flow chart of student participants 
AEDC cohort were eligible to participate in the WEC for the first time in 2015 when they were in Grade 6. Passive consent procedures were used with parents/guardians, and active consent procedures were used with students. In 2015, a total of 368 out of 719 invited schools were involved in the collection (school participation rate of $51.2 \%$ ). A total of 29,189 students from participating schools completed the survey in 2015 (student participation rate of 82\%), and data was available for linkage for 7069 Grade 6 students attending 282 Government/public schools (see Fig. 1). Students completed the WEC using an online data collection system, during a double class period $(2 \times 45 \mathrm{~min})$.

Data linkage was undertaken by DfE, and all identifying information was removed (i.e. name, address, date of birth) prior to receipt of the dataset for analysis to ensure confidentiality. The linkage was limited to students who attended a government/public school in both 2009 and 2015. Ethics approval for the current study was received from SA Human Research Ethics Committee (HREC/13/SAH/99). Additional information about the data linkage is provided below in the data analysis strategy, data linkage and imputation section.

\subsection{Participants}

The analysis sample included 3906 children who were included in the AEDC at school entry in $2009\left(\mathrm{M}_{\mathrm{age}}=5.6, \mathrm{SD}=0.28\right.$, Range $=4$ to 6 years $)$ and completed the WEC in Grade 6 in $2015\left(\mathrm{M}_{\text {age }}=11.9, \mathrm{SD}=0.28\right.$, Range $=9$ to 12 years $)$. Of those in the sample, $51.0 \%$ were male, $12.0 \%$ had a language background other than English, and $2.9 \%$ were of Aboriginal and/or Torres Strait Islander descent. Table 1 presents information on the demographic characteristics for the analysis sample $(n=3906)$, compared to the full South Australian population from the 2009 AEDC $(N=16,207)$, and the sub-set of government/public school students who participated in the 2009 AEDC $(N=10,908)$. In Australia about two thirds of students attend government/ public schools, $20 \%$ attend Catholic schools and 15\% attend Independent schools (Australian Bureau of Statistics 2018). Demographic characteristics of the analysis sample were similar to the sample of SA government/public school students who participated in the 2009 AEDC, with the analysis sample having a slightly lower percentage of Aboriginal and/or Torres Strait Islander children, children with a language background other than English, and children living in the most disadvantaged areas of the state.

\subsection{Measures}

\subsubsection{School Readiness (Age 5)}

The Australian version of the Early Development Instrument (AvEDI; Australian Government Department of Education 2009) was used as the measure of school readiness. The AvEDI is a teacher completed instrument that was adapted from the Canadian Early Development Instrument (EDI), developed at the Offord Centre for Child Studies (Janus and Offord 2007). It consists of 96 items measuring children's development across five developmental domains - Physical Health and Wellbeing, Social Competence, Emotional Maturity, Language and Cognitive Skills, and 
Table 1 Sociodemographic characteristics and child development results for the 2009 AEDC cohort (all students), the 2009 AEDC cohort (government students) and the final analysis sample used in the current study

\begin{tabular}{|c|c|c|c|c|c|c|}
\hline & \multirow{2}{*}{\multicolumn{2}{|c|}{$\begin{array}{l}2009 \text { AEDC cohort (all } \\
\text { SA students) } \\
N=16,207\end{array}$}} & \multirow{2}{*}{\multicolumn{2}{|c|}{$\begin{array}{l}2009 \text { AEDC cohort (SA } \\
\text { gov. students) } \\
N=10,908\end{array}$}} & \multirow{2}{*}{\multicolumn{2}{|c|}{$\begin{array}{l}\begin{array}{l}\text { Imputed, final } \\
\text { analysis sample }\end{array} \\
n=3906\end{array}$}} \\
\hline & & & & & & \\
\hline & $N$ & $\%$ & $N$ & $\%$ & $n$ & $\%$ \\
\hline \multicolumn{7}{|c|}{ Sociodemographic characteristics of students at school entry } \\
\hline \multicolumn{7}{|l|}{ Gender } \\
\hline Male & 8338 & 51.4 & 5736 & 52.6 & 1992 & 51.0 \\
\hline Female & 7869 & 48.6 & 5172 & 47.4 & 1914 & 49.1 \\
\hline \multicolumn{7}{|c|}{ Aboriginal and/or Torres Strait Islander status } \\
\hline No & 15,585 & 96.2 & 10,340 & 94.8 & 3792 & 97.1 \\
\hline Yes & 622 & 3.8 & 568 & 5.2 & 114 & 2.9 \\
\hline \multicolumn{7}{|l|}{ LBOTE } \\
\hline English background & 14,086 & 86.9 & 9449 & 86.5 & 3437 & 88.0 \\
\hline Non-English background & 2121 & 13.1 & 1459 & 13.5 & 469 & 12.0 \\
\hline \multicolumn{7}{|l|}{ Area of residence (Remoteness) } \\
\hline Major cities & 11,519 & 71.1 & 7387 & 67.8 & 2614 & 66.9 \\
\hline Inner regional & 1838 & 11.3 & 1234 & 11.3 & 422 & 10.8 \\
\hline Outer regional & 2200 & 13.6 & 1716 & 15.7 & 648 & 16.7 \\
\hline Remote & 478 & 2.9 & 406 & 3.7 & 171 & 4.4 \\
\hline Very remote & 172 & 1.1 & 158 & 1.4 & 47 & 1.2 \\
\hline \multicolumn{7}{|l|}{ Socio-economic status } \\
\hline Lowest (most disadvantaged areas) & 3933 & 24.4 & 2879 & 26.5 & 938 & 24.1 \\
\hline Low & 3702 & 22.9 & 2526 & 23.2 & 912 & 23.4 \\
\hline Middle & 3122 & 19.3 & 2059 & 18.9 & 763 & 19.6 \\
\hline High & 3095 & 19.2 & 1979 & 18.2 & 721 & 18.5 \\
\hline Highest (least disadvantaged areas) & 2292 & 14.2 & 1424 & 13.1 & 565 & 14.5 \\
\hline \multicolumn{7}{|c|}{ Child development (AvEDI) of students at school entry } \\
\hline \multicolumn{7}{|l|}{ Physical health and wellbeing } \\
\hline On track & 11,331 & 75.2 & 7209 & 70.8 & 2913 & 74.6 \\
\hline At Risk & 2228 & 14.8 & 1681 & 16.5 & 625 & 16.0 \\
\hline Vulnerable & 1503 & 10.0 & 1179 & 11.6 & 368 & 9.4 \\
\hline \multicolumn{7}{|l|}{ Social competence } \\
\hline On track & 11,093 & 73.6 & 7128 & 70.0 & 2944 & 75.4 \\
\hline At Risk & 2448 & 16.3 & 1780 & 17.5 & 625 & 16.0 \\
\hline Vulnerable & 1518 & 10.1 & 1158 & 11.4 & 337 & 8.6 \\
\hline \multicolumn{7}{|l|}{ Emotional maturity } \\
\hline On track & 11,146 & 74.3 & 7171 & 70.5 & 2963 & 75.9 \\
\hline At Risk & 2301 & 15.4 & 1676 & 16.5 & 569 & 14.6 \\
\hline Vulnerable & 1541 & 10.3 & 1175 & 11.5 & 374 & 9.6 \\
\hline
\end{tabular}


Table 1 (continued)

\begin{tabular}{|c|c|c|c|c|c|c|}
\hline & \multicolumn{2}{|c|}{$\begin{array}{l}2009 \text { AEDC cohort (all } \\
\text { SA students) }\end{array}$} & \multicolumn{2}{|c|}{$\begin{array}{l}2009 \text { AEDC cohort (SA } \\
\text { gov. students) }\end{array}$} & \multicolumn{2}{|c|}{$\begin{array}{l}\text { Imputed, final } \\
\text { analysis sample }\end{array}$} \\
\hline & \multicolumn{2}{|c|}{$N=16,207$} & \multicolumn{2}{|c|}{$N=10,908$} & \multicolumn{2}{|c|}{$n=3906$} \\
\hline & $N$ & $\%$ & $N$ & $\%$ & $n$ & $\%$ \\
\hline On track & 12,490 & 83.1 & 8071 & 79.3 & 3325 & 85.1 \\
\hline At Risk & 1627 & 10.8 & 1259 & 12.4 & 406 & 10.4 \\
\hline Vulnerable & 923 & 6.1 & 724 & 7.1 & 176 & 4.5 \\
\hline \multicolumn{7}{|c|}{ Communication skills and general knowledge } \\
\hline On track & 11,352 & 75.3 & 7172 & 70.5 & 2941 & 75.3 \\
\hline At Risk & 2509 & 16.7 & 1926 & 18.9 & 679 & 17.4 \\
\hline Vulnerable & 1200 & 8.0 & 970 & 9.5 & 286 & 7.3 \\
\hline
\end{tabular}

$A E D C$ Australian Early Development Census, $A v E D I$ Australian version of the Early Development Instrument, SA South Australia, LBOTE Language background other than English

Communication Skills and General Knowledge, each described below. These five scales were created following exploratory factor analyses, which suggested the EDI measured five unique latent factors (Janus and Offord 2007), and confirmatory factor analyses have found support for this factor structure in samples of Canadian, Jamaican, USA and Australian children (Janus et al. 2011).

Each child receives a score between 0 and 10 on each of the five domains (higher scores represent better development). For the purpose of reporting and monitoring child development in Australia, children also receive a categorical score based on their relative position in the distribution of scores from the first national census of child development completed in Australia in 2009 ( $n=261,147$ children, 97.5\% of the estimate eligible population). Children who scored below the 10th percentile were classified as developmentally 'vulnerable', scores between the 10th and 25th percentile were classified as 'at risk' and scores above the 25 th percentile were classified as 'on track' (see Brinkman et al. 2014 for details). For this study, the categorical variables (vulnerable, at risk, on track) for each of the five domains were used as the measures of school readiness in the analyses for two key reasons. First, the continuous domain scores are positively skewed with many children receiving the highest possible score of 10 on one or more domains. Second, to help facilitate the translation of these research findings into policy and practice within the Australian education system.

Physical Health and Wellbeing This domain consists of 12 items that measure three aspects of children's physical health and wellbeing: physical readiness for the school day, physical independence, and fine and gross motor skills (Janus and Offord 2007). Items include 'since the start of the school year, has this child sometimes (more than once) arrived hungry?', 'Would you say this child is well- co-ordinated?', and 'How would you rate this child's proficiency at holding a pen, crayon or brush?' Teachers answer using a Yes/No response scale for six of the items, and a 3-point rating scale (poor/very poor, average, very good/good) for the other six items. The scale has been 
shown to have good internal consistency in samples of children from Australia, Canada, and the United States $(\alpha=0.80,0.76$ and 0.82 , respectively, see Janus et al. 2011), and in the current sample $(\alpha=0.83)$.

Social Competence This domain consists of 24 items that measures four aspects of children's social skills: overall social competence, responsibility and respect towards adults and peers, approaches to learning, and children's readiness to explore new things (Janus and Offord 2007). Items include 'How would you rate this child's ability to get along with peers?', 'Would you say this child demonstrates self-control?', 'Would you say this child works independently?' and 'Would you say this child is eager to play with a new toy?". All 24 items in this scale were rated on a three-point response scale from "poor/very poor" to "very good/good" or "never or not true" to "often or very true". High internal consistency $(\alpha \geq 0.95)$ has been found for this scale in samples of children from Australia, Canada, and US (Janus et al. 2011), and in the current sample $(\alpha=0.95)$.

Emotional Maturity This scale consists of 26 items that measure four aspects of children's emotional maturity: prosocial skills, anxious and fearful behavior, aggressive behavior, and hyperactive and inattentive behavior. Items include 'Would you say this child will invite others to join in a game?', 'Would you say this child is nervous, highly strung or tense?', 'Would you say this child bullies or is mean to others?' and 'Would you say this child is distractible, has trouble sticking to any activity?' Teachers respond to these items using a three-point response scale (never or not true, sometimes, often or very true). High internal consistency $(\alpha \geq 0.90)$ for this scale has been found in samples of children from Australia, Canada, and US (Janus et al. 2011), as well as the current sample $(\alpha=0.93)$.

Language and cognitive skills This scale consists of 26 items and measures basic and advanced literacy skills, basic numeracy skills and children's level of interest in literacy, numeracy and memory skills. Items include 'Would you say this child is able to identify at least 10 letters of the alphabet?', 'Would you say this child is able to read simple words?', 'Would you say this child is able to sort and classify objects by a common characteristic (e.g., shape, colour, size)?', and 'Would you say this child is interested in games involving numbers?' All items in this scale were rated on a twopoint ("Yes/No") response scale. High internal consistency ( $\alpha=0.89$ to 0.91 ) for this scale has been found in samples of children from Australia, Canada, and US (Janus et al. 2011), and in the current sample $(\alpha=0.88)$. Given that English is the language of instruction in Australian schools, teachers rate children's basic and advanced literacy skills, as well as their oral communication skills in English.

Communication Skills and General Knowledge This scale consists of 8 items that measures children's oral communication skills and general knowledge using items including 'How would you rate this child's ability to use language effectively in English?', 'How would you rate this child's ability to tell a story?' and 'Would you say this child answers questions showing knowledge about the world?'. All items in this scale were rated on a three-point response scale from "poor/very poor" to "very good/good" or "never or not true" to "often or very true". This scale has high internal 
consistency ( $\alpha=0.90$ to 0.93 ) in samples of children from Australia, Canada, and US (Janus et al., 2011), including the current sample $(\alpha=0.92)$.

\subsubsection{Student Wellbeing in Grade 6 (Age 11)}

Student wellbeing data was collected using students' self-report responses on the Middle Years Development Instrument (MDI). The MDI is a population-level questionnaire that was developed in Canada for primary/elementary school students and has been validated in Canada and Australia (Gregory et al. 2019; Guhn et al. 2012; Schonert-Reichl et al. 2013). Four scales from the MDI (life satisfaction, optimism, sadness, and worries) were used as outcome measures in this study. Students receive a score between 1 and 5 on each of the MDI items and these are averaged to calculate a total scale score. All of these scales have been previously used in research with children in Canada and Australia, and the psychometric properties of the scales have been reported (details provided below for each specific scale). Exploratory and confirmatory factor analyses on the MDI in sample of Canadian Grade 4 students provide evidence that the scales used in this study represent unique factors, with convergent and discriminant validity and good internal reliability (Schonert-Reichl et al. 2013).

Life Satisfaction The Satisfaction with Life Scale - Adapted for Children (SWLS-C; Gadermann et al. 2010) is a 5-item scale that was modified from the adult Satisfaction with Life Scale. The scale includes items such as 'The things in my life are excellent' and 'I am happy with my life" and uses a 5-point response scale ('Disagree a lot' $=1$ to 'Agree a lot' = 5). This scale had high internal consistency in the current sample with Cronbach $\alpha=0.83$, which is consistent with findings from other studies (Gadermann et al. 2010; Gregory et al. 2019; Schonert-Reichl et al. 2013).

Optimism A 3-item optimism scale that was adapted from the Resiliency Inventory (Noam and Goldstein 1998) and includes items such as 'I start most days thinking I will have a good day' was used in the current study. Students responded using a 5-point likert scale ('Disagree a lot' $=1$ to 'Agree a lot' $=5$ ). The scale has been shown to have good internal consistency in samples of Canadian and Australian children (Gregory et al. 2019; Schonert-Reichl et al. 2013), as well as in the current sample (Cronbach's $\alpha=0.74)$.

Sadness The presence of sadness was measured using a 3-item scale that was designed to measure depressive symptoms and was adapted from the Depression sub-scale in the Seattle Personality Questionnaire (Kusche et al. 1988; Rains 2003). The scales includes items such as 'I feel unhappy a lot of the time' and uses a 5-point response scale ('Disagree a lot' $=1$ to 'Agree a lot' = 5). The internal consistency of the scale in the current sample was acceptable (Cronbach $\alpha=0.69$ ), and has been shown to range from 0.69 to 0.75 in samples of Australia children aged from 10 to 15 years (Gregory et al. 2019).

Worries The presence of worries/anxiety symptoms was measured using a 3-item scale that was adapted from the 6-item anxiety symptomology scale in the Seattle Personality 
Questionnaire (Kusche et al. 1988; Rains 2003). The scale includes items such as 'I worry a lot that other people might not like me' and 'I worry about what kids might be saying about me" using a 5-point response scale ('Disagree a lot' = 1 to 'Agree a lot' = $5)$. The scale had good internal consistency in the current sample (Cronbach $\alpha=0.86$ ), with Cronbach's alpha values ranging from 0.86 to 0.89 in samples of Australia children (Gregory et al. 2019).

\subsubsection{Covariates}

Sociodemographic characteristics of the student, extracted from the administrative records held by DfE, included gender, Aboriginal and/or Torres Strait Islander status, language background other than English (LBOTE), highest post-secondary school education level achieved for parent(s) and postal code of residence. A communitylevel measure of socio-economic status (SEIFA Index of Relative Socio-economic disadvantage) applied to each student based on their suburb/neighbourhood of residence was extracted from the AEDC data (Australian Bureau of Statistics 2011b). Student's living arrangements in Grade 6 was extracted from the WEC survey. Arealevel measures of geographical remoteness was applied to each student based on their postal code of residence in Grade 6. Geographical remoteness was based on the 2011 Remoteness Index of Australia (Australian Bureau of Statistics 2011a), which categorises areas into five categories - major cities, inner regional, outer regional, remote and very remote - based on their distance to service towns and their access to goods and services.

\subsection{Data Analysis Strategy, Data Linkage, and Imputation}

Data management was conducted using SPSS V26 and all analyses used Stata V16. The de-identified data provided by DfE represented the population of students attending government schools at the time of the $2009 \operatorname{AEDC}(N=10,908)$ data collection and the sample of Grade 6 students that completed the 2015 WEC ( $n=7069$, see Fig. 1$)$. Data were linked for a total of 4141 children, representing $38.0 \%$ of all children in government schools in the 2009 AEDC cohort. The main reasons for lack of data linkage are the movement of children from the government/public to non-government school sector, moving interstate/overseas between school entry and Grade 6, and nonparticipation in the 2015 WEC. To allow comparisons of the demographic characteristics and development of the analysis sample in this study with the broader population of Australian children who participated in the 2009 AEDC, a small number of students ( $n=211,5.0 \%$ ) with special needs were excluded. In addition, a small number of records $(n=24,0.6 \%)$ had missing data on all AvEDI and MDI scales so were excluded, leaving 3906 student records for analysis.

Of these 3906 students, $373(9.5 \%)$ had missing data on at least one independent or dependent variable, and $731(18.7 \%)$ had missing data on one or more covariates (gender, Aboriginal and Torres Strait Islander status, LBOTE, child living arrangement, parental education, community-level SES and geographical remoteness of residence) used in the regression modelling. Most variables had missing data for between $0 \%$ and 
$4 \%$ of cases, except for highest level of parental education, which was missing for $19 \%$ of cases.

To account for the potential bias of missing data in the matched sample, multiple imputation (MI) was conducted for the analysis sample $(n=3906)$ on missing predictor variables, covariates and/or outcomes (Sullivan et al. 2015). Auxiliary variables from both datasets were included to improve the imputation model, with a specific focus on variables that would be related to the missing parental education information. Auxiliary variables included highest occupation classification of parent(s), number of siblings, school ID, postcode, and other MDI scales that were measured but not the focus of the current study (empathy, prosocial behaviour, connectedness to adults at school, neighbourhood and at home, friendship intimacy, peer belonging, academic self-concept, school climate, school belonging and bullying). Since the data is a mixture of continuous, nominal and ordinal variables, MI by chained equations was conducted using the mi impute chained procedure in Stata. The number of imputed datasets was 50 with 30 iterations per imputed dataset. The imputed results did not differ greatly to the complete case analyses; therefore, only the imputed results are presented. The complete case analyses are available by request from the authors.

\subsubsection{Data Modelling Strategies}

A series of multiple linear regression analyses were conducted using the regress procedure for imputed data in Stata. The vce (cluster) procedure was used to account for the hierarchical nature of the data (i.e. children are nested within schools), using School ID (in Grade 6). The goal of this paper was to explore the association between each of the five aspects of school readiness and four student wellbeing outcomes, after adjusting for child and family level confounders, not to explore the joint contribution of different aspects of school readiness or the predictive validity of school readiness for student wellbeing. As such, for each of the five measures of school readiness and four student wellbeing measures, a linear regression model was run with a single independent variable (e.g. social competence at school entry) and single dependent variable (e.g. life satisfaction in Grade 6), to estimate the unadjusted association between school readiness and student wellbeing. A second linear regression model was run that added a set of child and family level characteristics as categorical predictor variables (gender, Aboriginal and/or Torres Strait Islander status, LBOTE, student's living arrangements, remoteness area index, highest educational status of parents and community-level socio-economic status), to estimate the adjusted association between school readiness and student wellbeing.

Table 2 reports the results of the unadjusted and adjusted multiple regression analyses where the coefficients for the at risk and vulnerable groups indicate how much the mean scores for these two groups deviate from the mean score for the on track group, before and after adjusting for child and family level covariates. Full regression model results including coefficients for each of the covariates are presented in Supplementary Tables 1-5. Estimated marginal mean scores on the student wellbeing measures in Grade 6 for children who were vulnerable, at risk and on track in school readiness from the fully adjusted model were estimated using the mimrgns procedure in Stata, and are reported in Supplementary Table 6. 


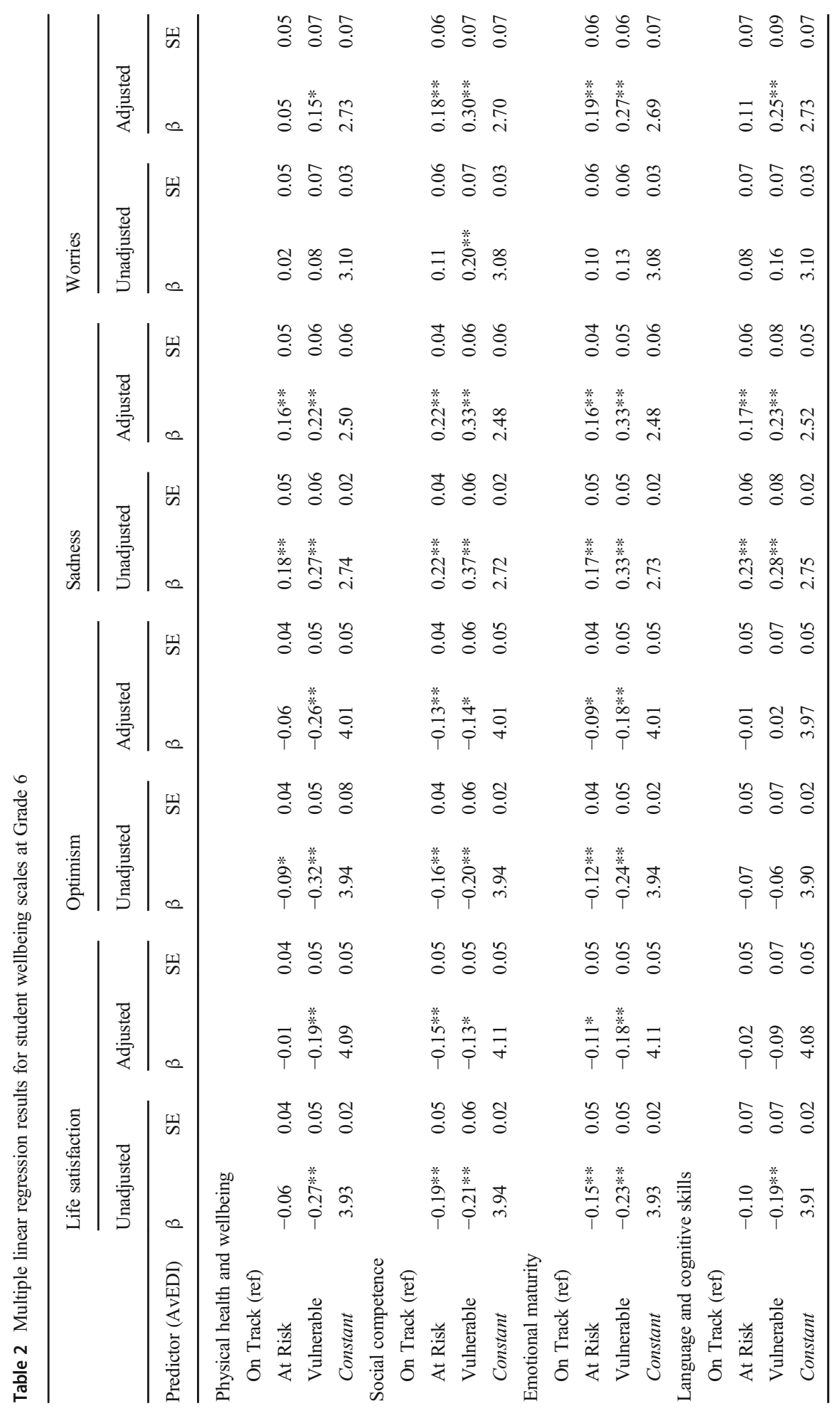




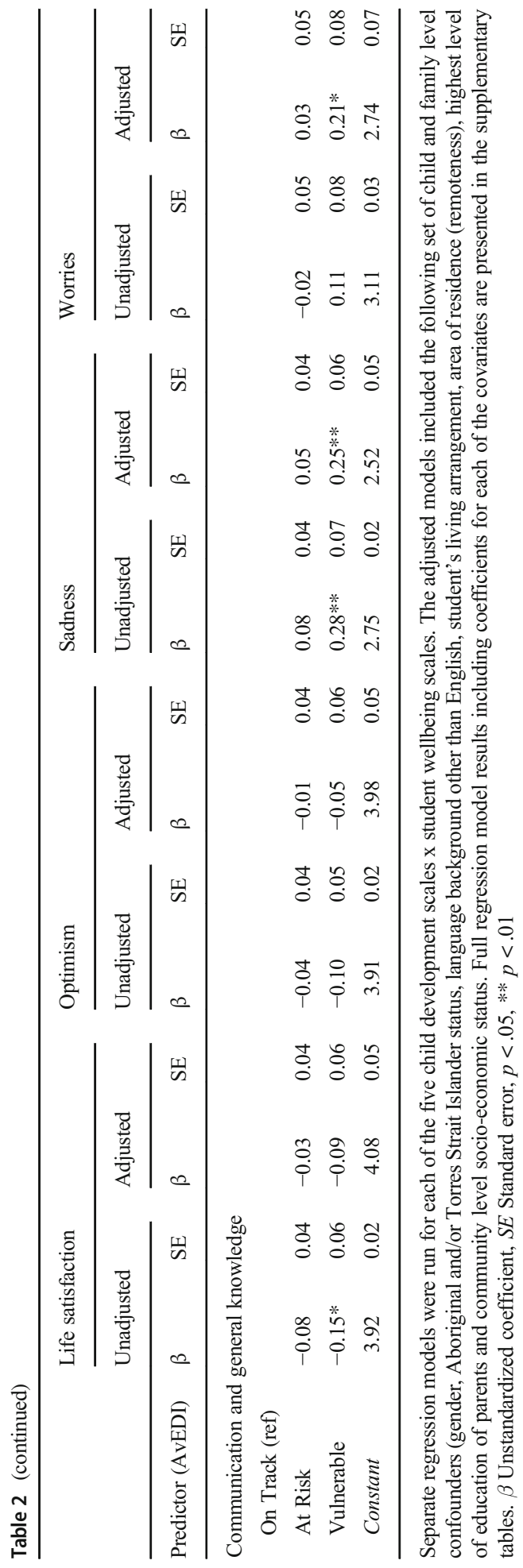




\section{Results}

Table 1 presents information on the demographic characteristics and school readiness results for the imputed analysis sample $(n=3906)$, compared to the full South Australian population from the $2009 \operatorname{AEDC}(N=16,207)$, and the sub-set of government/public school students who participated in the 2009 AEDC $(N=10,908)$. Compared to the South Australia population in the 2009 AEDC, children who attended public schools were slightly more likely to be developmentally vulnerable on each of the five domains. For instance, about $10 \%$ of SA children were developmentally vulnerable in social and emotional development at school entry, compared to 11$12 \%$ of children who attended public schools. Children in the imputed analysis sample were even less likely to be developmentally vulnerable with about 8-10\% of children vulnerable in social and emotional development. As such, the linked analysis sample had slightly higher levels of school readiness (on all five domains) than the population of South Australian children in the 2009 AEDC.

Children who were vulnerable in physical health and wellbeing at school entry had lower levels of life satisfaction and optimism and higher levels of sadness and worries in Grade 6 than children who were on track. In most cases, effect estimates were attenuated after adjusting for child and family level confounders. For example, children who were vulnerable scored 0.27 points lower score on life satisfaction in Grade 6 than children who were on track, and this reduced to 0.19 points after adjustment for confounders. In contrast, effect estimates for the worries scales in Grade 6 were slightly higher after adjustment for confounders and this was observed for all five domains of child development.

Social competence and emotional maturity at school entry were associated with all four student wellbeing outcomes (life satisfaction, optimism, sadness and worries) in Grade 6. Children who were vulnerable or at risk in these developmental domains had poorer wellbeing in Grade 6, with effect estimates higher for the vulnerable children compared with the at risk children for most outcomes. For example, compared to children who were on track in their emotional maturity at school entry, children who were at risk scored 0.16 points higher in sadness in Grade 6 and children who were vulnerable scored 0.33 points higher in sadness in the adjusted models.

The pattern of associations between school readiness and student wellbeing was somewhat different for children's language and communion skills at school entry. Children who were vulnerable in their language and cognitive skills and/or communication and general knowledge skills at school entry demonstrated lower levels of sadness and worries in Grade 6 than children who were on track, but there were no difference in their level of life satisfaction or optimism in adjusted models. Fig. 2 is provided for illustrative purposes and shows the adjusted associations between all five school readiness domains and one student wellbeing outcome (sadness).

\section{Discussion}

Many studies have shown that school readiness is associated with later academic achievement (see La Paro and Pianta 2000 for review), but the association between school readiness and students later social and emotional wellbeing is less well 
4.0

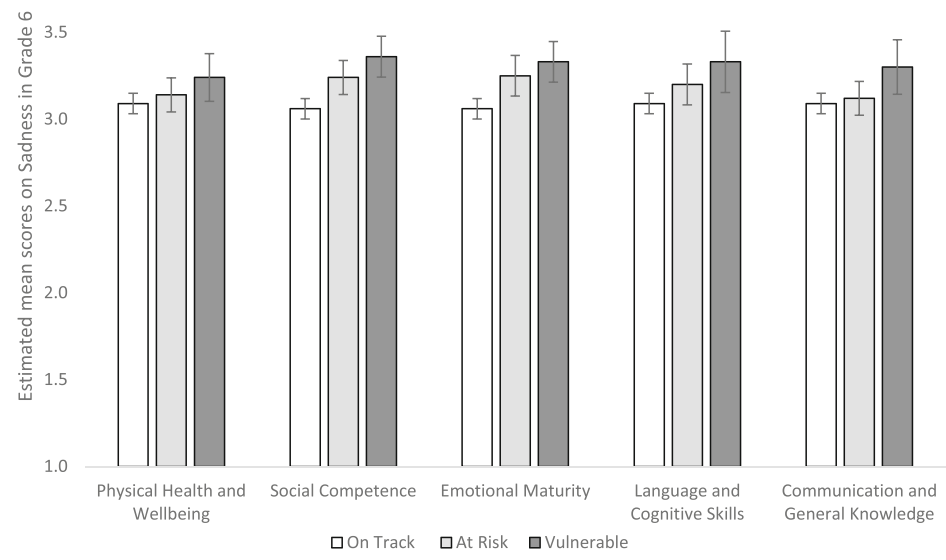

Fig. 2 Estimated marginal means on Grade 6 Sadness $x$ school readiness. Note. Error bars are 95\% confidence intervals.

understood. This paper sought to explore the association between five different aspects of school readiness/early development and students' social and emotional wellbeing in late primary/elementary school. Consistent with expectations, students' social competence and emotional maturity at school entry were associated with both positive (life satisfaction, optimism) and negative (sadness, worries) aspects of students' social and emotional wellbeing in Grade 6, after adjusting for child and family level confounders. Somewhat surprisingly, children's physical health and wellbeing at school entry was associated with all four aspects of student wellbeing, In order to unpack these findings, it is useful to understand how physical health and wellbeing was measured in the current study.

The physical health and wellbeing scale from the Australian version of the Early Development Instrument (see Brinkman et al. 2014, for a full list of items) measures several different aspects of physical health and wellbeing, including whether children come to school hungry, tired, sick, or dressed inappropriately for school-related activities, their energy levels throughout the day, physical hygiene and their gross and fine motor skills. As such, there are a range of different mechanism through which physical health and wellbeing might impact students' social and emotional wellbeing. For instance, if a child is coming to school hungry, tired, dressed inappropriately, or with poor physical hygiene, this may indicate that the family is facing some challenges in the home (e.g. parental stress, financial difficulties, mental health problems) that impact on the child's readiness for the school day, and may have long-term impacts on the child's wellbeing. These types of barriers are more prevalent for families experiencing high socioeconomic disadvantage, and there is also a socioeconomic gradient in many mental health and wellbeing outcomes (Reiss 2013; West et al. 2020). As such, the physical health and wellbeing scale may be capturing aspects of socio-economic status that are also related to students' social and emotional wellbeing, explaining the association between the two measures. While the analyses in this study adjusted for some SES indicators (child living arrangement, parental education, community-level 
socio-economic status, geographical remoteness of residence), it is possible that there was additional unmeasured confounding.

Another possibility is that the link between physical health and wellbeing and social and emotional wellbeing reflects an association between fine and gross motor skills and social and emotional wellbeing. Children with better developed fine and gross motor skills in early childhood have been shown to have better reading and mathematics skills in primary school (Grissmer et al. 2010), as well as stronger social and emotional skills (Bart et al. 2007). For example, Bart et al. (2007) showed that muscle tone and general motor functioning in kindergarten was associated with fewer anxious-withdrawn behaviors during the transition to school, and that visual-spatial perception and general motor function were associated with fewer disruptive and more prosocial behaviors. Research has also shown a socioeconomic gradient in motor development, with children attending more disadvantaged schools having poorer manual dexterity, ball skills and balance compared to children in more advantaged schools (McPhillips and Jordan-Black 2007). As such, it is likely that both SES and gross and fine motor skills mediate the association between physical health and wellbeing and later student wellbeing.

This study also sought to understand the associations between language and cognitive skills and later student wellbeing given the mixed findings in previous research. While some previous studies found that academic skills (language, cognitive, literacy, numeracy) were among the strongest predictors of social and emotional wellbeing (Romano et al. 2010; Sabol and Pianta 2012), others found they were not significant predictors once early social and emotional skills were accounted for (Guhn et al. 2016). Our study found that better language and cognitive skills, as well as communication and general knowledge skills were associated with lower levels of sadness and worries in Grade 6 but not higher life satisfaction or optimism, suggesting that the association between language/communication skills and student wellbeing might depend on whether positive or negative aspects of wellbeing are measured.

The association between language skills and internalising behaviour (sadness and worries) observed in the current study is consistent with findings from a recent systematic review and meta-analysis which estimated a mean effect size between language ability and internalising behaviours of -0.11 in school aged children (Chow and Wehby 2018). It is also consistent with Romano et al. (2010) who found maths skills significantly predicted internalising and externalising problems after adjusting for earlier social and emotional skills.

One possible explanation of the link between language skills and internalising behaviours is that well-developed language and communication skills may help children to describe and understand their emotions, utilise more healthy emotion regulation strategies, and negotiate conflicts with other children (see Eisenberg et al. 2005), and these skills have been shown to help reduce the likelihood of internalising problems in middle childhood (Trentacosta and Fine 2010). For example, as children's language and cognitive skills develop they are more able to utilise a wider range of emotion regulation strategies such as cognitive reappraisal, which involves thinking about a situation in a different way to alter their emotional state rather than relying on emotion regulation techniques that focus on inhibiting and internalising their emotions. As summarised by Gross (2013), use of cognitive reappraisal techniques are associated with experiencing more positive and less negative emotions, fewer depressive 
symptoms, and more positive relationships with others, and thus it is plausible that better developed language and communication skills at school entry may impact later internalising problems through the access to and use of better emotion regulation strategies.

Given that multiple aspects of school readiness are associated with later social and emotional wellbeing up to 6 years later, interventions aimed at improving early childhood development have the potential to have longer term impact on wellbeing in the middle years. However, it is important to note that while school readiness was associated with later student wellbeing, these effects were small, and shorter follow up periods (i.e. more proximal measures of school readiness and student wellbeing) are likely to generate stronger associations between the two constructs. Other studies have typically found slightly stronger associations between school readiness and social and emotional wellbeing, but the follow up period has been shorter. For example, La Paro and Pianta (2000) used meta-analytic approaches to estimate a mean correlation of .29 between measures of school readiness and social and emotional development, with just 12 years between the two observations. Studies with a longer follow up period have found small associations of a similar magnitude to those in the current study. For example, Guhn et al. (2016) found correlations of .11, .12 and .05 between measures of social, emotional and language development at school entry and emotional wellbeing in Grade 4. As such, the findings in this study are largely consistent with previous literature showing a small but significant association between children's school readiness across multiple domains and their social and emotional wellbeing in later primary/elementary school.

From a pragmatic perspective, it is also important to consider where schools, educators and governments can provide effective change and where they are likely to get the best returns on their investments. While there is a wealth of evidence to support the effectiveness of social and emotional learning (SEL) programs for children's social, emotional and academic outcomes (see Taylor et al. 2017, for recent review), information on the cost benefits of these programs as well as the most effective timing and sequencing of lessons and curricula is less well understood. Within an education system with finite resources, governments need to consider whether building social and emotional skills during early childhood through preschool and early learning centres is more (or less) cost effective than school-based social and emotional learning programs for older children, and evidence about the size of impacts of SEL programs during early childhood compared with later schooling will help to guide these decisions (Belfield et al. 2015). Similarly, governments may have more leverage to impact on children's relationships with adults at school (e.g. teachers) than their relationships with their parents, however, relationships with adults at home are more strongly associated with student's life satisfaction than their relationships with adults at school (Gadermann et al. 2016). In the current study, children's living arrangements in Grade 6 showed one of the strongest associations with wellbeing, highlighting the importance of a healthy, supportive home environment to student's wellbeing, as well as the idea that early childhood development is one of a range of different factors that impact on student wellbeing.

One limitation of this study was that school readiness data was only available for linkage for children attending government/public schools, and student wellbeing data in Grade 6 was only available for $36 \%$ of these children. The analysis sample had better school readiness than the population of South Australian children from the 2009 AEDC, and also had a slightly lower percentage of children with a language background other 
than English, and children living in the most disadvantaged areas of the state. It is possible that this may have led to a reduction in the variation in school readiness and social and emotional wellbeing outcomes, and an underestimate of the school readiness/social and emotional wellbeing relationships. School-level participation rates in the student wellbeing collection (WEC) for government/public schools in South Australia have increased markedly over the past few years from $65 \%$ to over $90 \%$ between 2015 and 2018, and child-level participation rates have remained high (see Gregory et al. 2019). As such, future studies on more recent cohorts of children could access a more representative sample of children to replicate these analyses.

To summarise, this study provides evidence that children's physical, social, emotional, language and communication skills when entering full time school are associated with their social and emotional wellbeing in sixth grade. As expected, associations were strongest between social and emotional development at school entry and students' social and emotional wellbeing in Grade 6. Children's physical development at school entry was associated with all four social and emotional wellbeing outcomes in Grade 6, and we theorise that this may be explained in part by the established links between children's socio-economic status, fine and gross motor skills social and emotional wellbeing/ internalising behaviours. Children's language and communication skills were associated with internalising behaviours (sadness and worries) but not measures of positive wellbeing (life satisfaction and optimism), and we theorise that these relationships may be explained in part by children with better language skills having access to a wider range of emotion regulation strategies. Overall, this study found small but significant associations between school readiness and students' social and emotional wellbeing in Grade 6, and if this relationship is causal then interventions in the early years that improve child development may have flow on effects to students' social and emotional wellbeing in late primary/elementary school.

Acknowledgements The authors would like to thank the schools, teachers and students who have participated in the Australian Early Development Census (AEDC) and the Wellbeing and Engagement Collection (WEC). We would also like to acknowledge the valuable suggestions and feedback provided by reviewers.

Availability of Data and Material Data for this study was provided by the South Australian Department for Education to the research team for analysis. To gain access to the data for this manuscript, ethics approval and approval from the DfE were sought and granted, but the authors do not have permission to place the data into a data depository. Enquiries regarding requests to access the South Australian student wellbeing data can be directed to the DfE Research Unit (education.dma@sa.gov.au).

Funding Information This work was supported by an Australian Research Council Linkage Grant (\#LP130100535) to Associate Professor Sally Brinkman (CIA). Several of the authors (Tess Gregory, David Engelhardt, Martin Guhn, Anne Gadermann, and Kimberly Schonert-Reichl) were also named investigators on the grant.

\section{Compliance with Ethical Standards}

Conflicts of Interest/Completing Interests The authors declare that they have no conflict of interest.

Open Access This article is licensed under a Creative Commons Attribution 4.0 International License, which permits use, sharing, adaptation, distribution and reproduction in any medium or format, as long as you give 
appropriate credit to the original author(s) and the source, provide a link to the Creative Commons licence, and indicate if changes were made. The images or other third party material in this article are included in the article's Creative Commons licence, unless indicated otherwise in a credit line to the material. If material is not included in the article's Creative Commons licence and your intended use is not permitted by statutory regulation or exceeds the permitted use, you will need to obtain permission directly from the copyright holder. To view a copy of this licence, visit http://creativecommons.org/licenses/by/4.0/.

\section{References}

Australian Bureau of Statistics. (2011a). 1270.0.55.005 - Australian Statistical Geography Standard (ASGS): Volume 5 - Remoteness Structure, July 2011. Retrieved from http://www.abs.gov.au/ausstats/abs@. nsf/mf/1270.0.55.005?OpenDocument

Australian Bureau of Statistics. (2011b). Information Paper: An introduction to Socio-Economic Indexes for Areas (SEIFA) (cat.no. 2039.0). Retrieved from http://www.abs.gov.au/ausstats/abs@.nsf/mf/2039.0/.

Australian Bureau of Statistics. (2018). 4221.0 - Schools, Australia, 2017. http://www.abs.gov. au/ausstats/abs@.nsf/mf/4221.0

Australian Government Department of Education. (2009). 2009 AEDC Early Development Instrument and response criteria. Retrieved from www.aedc.gov.au/data-users/early-development-instrument/

Bart, O., Hajami, D., \& Bar-Haim, Y. (2007). Predicting school adjustment from motor abilities in kindergarten. Infant and Child Development, 16(6), 597-615. https://doi.org/10.1002/icd.514.

Belfield, C. R., Bowden, B., Klapp, A., Levin, H., Shand, R., \& Zander, S. (2015). The economic value of social and emotional learning. Journal of Benefit-Cost Analysis, 6(3), 508-544. https://doi.org/10.1017 /bca.2015.55.

Brinkman, S., Gregory, T., Goldfeld, S., Lynch, J., \& Hardy, M. (2014). Data resource profile: The Australian early development index (AEDI). International Journal of Epidemiology, 43(4), 1089-1096. https://doi. org/10.1093/ije/dyu085.

British Columbia Ministry of Education. (2015). BCs New Curriculum. Retrieved from https://curriculum. gov.bc.ca/

Chow, J. C., \& Wehby, J. H. (2018). Associations between language and problem behavior: A systematic review and correlational meta-analysis. Educational Psychology Review, 30(1), 61-82. https://doi. org/10.1007/s10648-016-9385-Z.

Collie, R. J., Martin, A. J., Nassar, N., \& Roberts, C. L. (2018). Social and emotional behavioral profiles in kindergarten: A population-based latent profile analysis of links to socio-educational characteristics and later achievement. Journal of Educational Psychology. https://doi.org/10.1037/edu0000262.

Department for Education. (2020). About the wellbeing and engagement collection Retrieved from https://www.education.sa.gov.au/department/research-and-data/wellbeing-engagement-collection

Diener, E., Eunkook, S., Richards, L., \& Smith, H. L. (1999). Subjective well-being: Three decades of Progress. Psychological Bulletin, 125(2), 276-302.

Eisenberg, N., Sadovsky, A., \& Spinrad, T. L. (2005). Associations of emotion-related regulation with language skills, emotion knowledge, and academic outcomes. New Directions for Child and Adolescent Development, 2005(109), 109-118. https://doi.org/10.1002/cd.143.

Gadermann, A. M., Guhn, M., Schonert-Reichl, K. A., Hymel, S., Thomson, K., \& Hertzman, C. (2016). A population-based study of Children's well-being and health: The relative importance of social relationships, health-related activities, and income. Journal of Happiness Studies, 17(5), 1847-1872. https://doi. org/10.1007/s10902-015-9673-1.

Gadermann, A. M., Schonert-Reichl, K. A., \& Zumbo, B. D. (2010). Investigating validity evidence of the satisfaction with life scale adapted for children. Social Indicators Research, 96(2), 229-247. https://doi. org/10.1007/s11205-009-9474-1.

Green, M. J., Tzoumakis, S., Laurens, K. R., Dean, K., Kariuki, M., Harris, F., Brinkman, S. A., \& Carr, V. J. (2019). Early developmental risk for subsequent childhood mental disorders in an Australian population cohort. Australian \& New Zealand Journal of Psychiatry, 53(4), 304-315. https://doi.org/10.1177 /0004867418814943.

Greenspoon, P. J., \& Saklafske, D. H. (2001). Toward an integration of subjective well-being and psychopathology. Social Indicators Research, 54, 81-108. 
Gregory, T., Engelhardt, D., Lewkowicz, A., Luddy, S., Guhn, M., Gadermann, A., et al. (2019). Validity of the middle years development instrument for population monitoring of student wellbeing in Australian school children. Child Indicators Research, 12(3), 873-899. https://doi.org/10.1007/s12187-018-9562-3.

Grissmer, D., Grimm, K. J., Aiyer, S. M., Murrah, W. M., \& Steele, J. S. (2010). Fine motor skills and early comprehension of the world: Two new school readiness indicators. Developmental Psychology, 46(5), $1008-1017$.

Gross, J. (2013). Emotion regulation: Taking stock and moving forward. Emotion, 13(3), 359-365.

Guhn, M., Gadermann, A. M., Almas, A., Schonert-Reichl, K. A., \& Hertzman, C. (2016). Associations of teacher-rated social, emotional, and cognitive development in kindergarten to self-reported wellbeing, peer relations, and academic test scores in middle childhood. Early Childhood Research Quarterly, 35, 76-84. https://doi.org/10.1016/j.ecresq.2015.12.027.

Guhn, M., Schonert-Reichl, K. A., Gadermann, A. M., Marriott, D., Pedrini, L., Hymel, S., \& Hertzman, C. (2012). Well-being in middle childhood: An assets-based population-level research-to-action project. Child Indicators Research, 5(2), 393-418. https://doi.org/10.1007/s12187-012-9136-8.

Janus, M., Brinkman, S., \& Duku, E. (2011). Validity and psychometric properties of the early development instrument in Canada, Australia, United States and Jamaica. Social Indicators Research, 103(2), 283-297. https://doi.org/10.1007/s11205-011-9846-1.

Janus, M., \& Offord, D. (2007). Development and psychometric properties of the early development instrument (EDI): A measure of children's school readiness. Canadian Journal of Behavioural Science, 39, 1-22. https://doi.org/10.1037/cjbs2007001.

Jones, D. E., Greenberg, M. T., \& Crowley, M. (2015). Early social-emotional functioning and public health: The relationship between kindergarten social competence and future wellness. American Journal of Public Health, 105(11), 2283-2290. https://doi.org/10.2105/AJPH.2015.302630.

Kern, M. L., Waters, L. E., Aldler, A., \& White, M. A. (2015). A multidimensional approach to measuring wellbeing in students: Application of the PERMA framework. The Journal of Positive Psychology, 10(3), 262-271.

Kusche, C. A., Greenberg, M. T., \& Beilke, R. (1988). Seattle personality questionnaire for young school-aged children. Unpublished personality questionnaire: University of Washington, Department of Psychology, Seattle.

La Paro, K. M., \& Pianta, R. C. (2000). Predicting Children's competence in the early school years: A metaanalytic review. Review of Educational Research, 70(4), 443-484. https://doi.org/10.3102 /00346543070004443.

McPhillips, M., \& Jordan-Black, J. (2007). The effect of social disadvantage on motor development in young children: A comparative study. Journal of Child Psychology and Psychiatry, 48(12), 1214-1222. https://doi.org/10.1111/j.1469-7610.2007.01814.x.

Ministerial Council for Education Early Childhood Development and Youth Affairs. (2008). Melbourne declaration on educational goals for young Australians. Retrieved from http://www.curriculum.edu. au/verve/_resources/National_Declaration_on_the_Educational_Goals_for_Young_Australians.pdf

Ministry of Education Singapore. (2015). Social and emotional learning. Retrieved from http://www.moe. gov.sg/education/programmes/social-emotional-learning

Noam, G. G., \& Goldstein, L. S. (1998). The resilience inventory: Unpublished Protocol.

OECD. (2015). Skills for Social Progress: the power of social and emotional skills Paris: OECD publishing.

Orejudo, S., Puyuelo, M., Fernández-Turrado, T., \& Ramos, T. (2012). Optimism in adolescence: A crosssectional study of the influence of family and peer group variables on junior high school students. Personality and Individual Differences, 52(7), 812-817. https://doi.org/10.1016/j.paid.2012.01.012.

Rains, C. (2003). Seattle personality questionnaire (grade 3+) - Technical Report on Fast Track project.

Reiss, F. (2013). Socioeconomic inequalities and mental health problems in children and adolescents: A systematic review. Social Science \& Medicine, 90, 24-31. https://doi.org/10.1016/j. socscimed.2013.04.026.

Romano, E., Babchishin, L., Pagani, L. S., \& Kohen, D. (2010). School readiness and later achievement: Replication and extension using a Nationwide Canadian survey. Developmental Psychology, 46(5), 9951007. https://doi.org/10.1037/a0018880.

Sabol, T. J., \& Pianta, R. C. (2012). Patterns of school readiness forecast achievement and Socioemotional development at the end of elementary school. Child Development, 83(1), 282-299. https://doi. org/10.1111/j.1467-8624.2011.01678.x.

Schonert-Reichl, K. A., Guhn, M., Gadermann, A. M., Hymel, S., Sweiss, L., \& Hertzman, C. (2013). Development and validation of the middle years development instrument (MDI): Assessing Children's well-being and assets across multiple contexts. Social Indicators Research, 114, 345-369. https://doi. org/10.1007/s1 1205-012-0149-y. 
Seligman, M. E. P., \& Csikszentmihalyi, M. (2000). Positive psychology: An introduction. American Psychologist, 55(1), 5-14. https://doi.org/10.1037/0003-066x.55.1.5.

Smith, S. R. (2007). Making sense of multiple informants in child and adolescent psychopathology: A guide for clinicians. Journal of Psychoeducational Assessment, 25(2), 139-149. https://doi.org/10.1177 /0734282906296233.

Soutter, A. K., O'Steen, B., \& Gilmore, A. (2014). The student well-being model: A conceptual framework for the development of student well-being indicators. International Journal of Adolescence and Youth, 19(4), 496-520. https://doi.org/10.1080/02673843.2012.754362.

Sullivan, T. R., Salter, A. B., Ryan, P., \& Lee, K. J. (2015). Bias and precision of the "multiple imputation, then deletion" method for dealing with missing outcome data. American Journal of Epidemiology, 182(6), 528-534. https://doi.org/10.1093/aje/kwv100.

Taylor, R. D., Oberle, E., Durlak, J. A., \& Weissberg, R. P. (2017). Promoting positive youth development through school-based social and emotional learning interventions: A meta-analysis of follow-up effects. Child Development, 88(4), 1156-1171. https://doi.org/10.1111/cdev.12864.

Thomson, K. C., Schonert-Reichl, K. A., \& Oberle, E. (2015). Optimism in early adolescence: Relations to individual characteristics and ecological assets in families, schools, and neighborhoods. An Interdisciplinary Forum on Subjective Well-Being, 16(4), 889-913. https://doi.org/10.1007/s10902-0149539-y.

Trentacosta, C. J., \& Fine, S. E. (2010). Emotion knowledge, social competence, and behavior problems in childhood and adolescence: A meta-analytic review. Social Development, 19(1), 1-29. https://doi. org/10.1111/j.1467-9507.2009.00543.x.

West, M. R., Pier, L., Fricke, H., Hough, H., Loeb, S., Meyer, R. H., \& Rice, A. B. (2020). Trends in student social-emotional learning: Evidence from the first large-scale panel student survey. Educational Evaluation and Policy Analysis, 42(2), 279-303. https://doi.org/10.3102/0162373720912236.

World Health Organization. (2008). Inequalities in young people's health: Health behaviour in school-aged children international report from the 2005/2006 survey. Retrieved from Scotland, UK: http://www.euro. who.int/en/publications/abstracts/inequalities-in-young-peoples-health.-hbsc-international-report-fromthe-20052006-survey

World Health Organization. (2012). Social determinants of health and well-being among young people. Health Behaviour in School-aged Children (HBSC) study: international report form the 2009/2010 survey. Retrieved from Copenhagen, WHO Regional Office for Europe: http:/www.euro.who. int/en/publications/abstracts/social-determinants-of-health-and-well-being-among-young-people.-healthbehaviour-in-school-aged-children-hbsc-study

Publisher's Note Springer Nature remains neutral with regard to jurisdictional claims in published maps and institutional affiliations.

\section{Affiliations}

\section{T. Gregory ${ }^{1,2} \cdot$ E. Dal Grande ${ }^{1} \cdot$ M. Brushe ${ }^{1,2} \cdot$ D. Engelhardt ${ }^{3} \cdot$ S. Luddy ${ }^{3} \cdot M$. Guhn $^{4} \cdot$ A. Gadermann ${ }^{4}$ - K.A. Schonert-Reichl ${ }^{5}$. S. Brinkman ${ }^{1,2}$}

1 Telethon Kids Institute, University of Western Australia, Perth, Australia

2 School of Public Health, University of Adelaide, Adelaide, Australia

3 South Australian Department for Education, Adelaide, Australia

4 The Human Learning Partnership, University of British Columbia, Vancouver, Canada

5 Department of Educational and Counselling Psychology, and Special Education, University of British Columbia, Vancouver, Canada 